\title{
Immunological alterations found in mesothelioma patients and supporting experimental evidence
}

\author{
Yoshie Miura Yasumitsu Nishimura $\cdot$ Megumi Maeda Shuko Murakami · \\ Hiroaki Hayashi · Kazuya Fukuoka · Takumi Kishimoto · Takashi Nakano • \\ Takemi Otsuki
}

Received: 27 June 2007/ Accepted: 31 July 2007/Published online: 28 February 2008

(C) The Japanese Society for Hygiene 2008

\begin{abstract}
It is common knowledge that exposure to asbestos causes asbestos-related diseases, such as asbestosis, lung cancer and malignant mesothelioma, not only in people who have had long-term contact with asbestos in their work environment but also in residents living near factories that handle asbestos. Since the summer of 2005 , these revelations turned into a large medical problem and caused and social unrest. We have focused on the immunological effects of both asbestos and silica on the human immune system. In this brief review, we introduce immunological alterations found in patients with malignant mesothelioma and describe the experimental background in which these were found. Analyzing the immunological effects of asbestos may improve our understanding of the biological effects of asbestos.
\end{abstract}

Keywords Asbestos · Chrysotile · Immunology · Mesothelioma

Y. Miura · Y. Nishimura $\cdot$ M. Maeda - S. Murakami ·

H. Hayashi · T. Otsuki $(\square)$

Department of Hygiene, Kawasaki Medical School,

577 Matsushima, Kurashiki 701-0192, Japan

e-mail: takemi@med.kawasaki-m.ac.jp

K. Fukuoka $\cdot$ T. Nakano

Department of Respiratory Medicine,

Hyogo Medical College of Medicine,

1-1 Mukogawa-cho, Nishinomiya 663-8131, Japan

T. Kishimoto

Okayama Rosai Hospital,

1-10-25 Chikkou-midori-machi,

Okayama 702-8055, Japan

\section{Introduction}

Asbestos is a generic name for a group of silicate minerals (complexes containing metals, such as iron and magnesium), the most common of which are chrysotile, crocidolite, and amosite. Patients exposed to asbestos develop pulmonary fibrosis, commonly called asbestosis, mesothelial plaque and malignant diseases, such as lung cancer and malignant mesothelioma (MM) [1-3]. Some of these malignancies may be considered to be a result of a decline in tumor immunity owing to the exposure of immunocompetent cells to asbestos.

Silica is known to be one of the most hazardous environmental substances in terms of causing autoimmunity dysfunction [4-6]. Silicosis patients often develop immunological complications, such as rheumatic arthritis (known as Caplan syndrome; [7-9], systemic sclerosis (SSc) and systemic lupus erythematoses (SLE). The effects of silica on autoimmunity have also been assumed as patients who receive plastic surgery with implants containing silicone $\left(\left[\mathrm{SiO}_{2}-\mathrm{O}-\right]_{n}\right)$ also frequently develop complications related to autoimmune disorders [10-12]. Taken together, these findings clearly indicate that crystalline silica causes dysregulation and/or disturbance of the human immune system in general, and of autoimmunity in particular.

Asbestos may affect human immunocompetent cells, and these alterations may, in turn, influence the occurrence and progression of asbestos-related malignant diseases, such as MM. For this reason, this article focuses on the immunological effects of asbestos. Chrysotile has been the most commonly used type of asbestos in our experiments. Magnesium, the main compartment of chrysotile as a silicate, usually dissociates from the chrysotile core, $\mathrm{SiO}_{2}$, in the human body 
Fig. 1 Comparison of $b c l-2$ relative expression ratio (RER) in peripheral blood CD4+ $\mathrm{T}$ cells among healthy volunteers, asbestosis patients and malignant mesothelioma (MM) patients. Peripheral blood mononuclear cells (PBMCs) were isolated from heparinized blood of healthy donors and from patients with asbestosis and MM using a Ficoll-Hypaque density gradient (Separate-L; Muto Pure Chemicals, Tokyo, Japan). For the isolation of CD4+ T cells, PBMCs were further separated using magnetic cell separation (MACS) CD4 MicroBeads (Miltenyi Biotech, Bergisch Gladbach, Germany) according to the manufacturer's instructions. The enriched cells were $>90 \%$ pure as determined by flow cytometry. Specimens were taken from healthy volunteers and patients from whom informed consent had been obtained. The Institutional Ethics Committee of Kawasaki Medical School, Hyogo College of Medicine, and Okayama Rosai Hospital approved the project. A fluorescence thermocycler (Mx3000P QPCR System; Stratagene, La Jolla, CA) was used for real-time reverse transcriptase (RT)-PCR experiments following the instructions of the manufacturer. With this technique, the fluorescence-labeled amplification product is measured continuously. Total RNA obtained from CD4+ T cells isolated from peripheral CD4+ T cells was extracted using an RNA Bee kit (Tel-Test, Friendswood, $\mathrm{TX}$ ), and $5 \mu \mathrm{g}$ of RNA was reverse-transcribed with standard methods using a RevertAid $\mathrm{H}$ Minus First Strand cDNA Synthesis lit (Fermentas, Ontario, Canada). An amount of cDNA equivalent to $50 \mathrm{ng}$ of RNA served as the template for PCR in a volume of $20 \mu \mathrm{l}$ (each primer and SYBER Premix Ex Taq; TaKaRa, Japan). The primers for $b c l-2$ and gapdh were added to the same reaction tube at the optimal concentration for each primer set, and PCR was performed. The primers were as follows: Bcl-2 [5'-TGATGTGAG TCTGGGCTGAG-3' (forward: Fw) and 5'-GAACGCTTTGTCCA GAGGAG- $3^{\prime}$ (reverse, Rv)]; Bax [5'-AGTAACATGGAGCTGCA GAGG-3' (Fw) and $5^{\prime}$-ATGGTTCTGATCAGTTCCGG-3' (Rv)]; GAPDH [5'-GAGTCAACGGATTTGGTCGT-3' (Fw) and 5'-TTGA TTTTGGAGGGATCTCG-3' $\left.3^{\prime}(\mathrm{Rv})\right]$. The relative expression of various target genes, such as $b c l-2$, was calculated when real-time RT-PCR was performed. The relative level of the target gene is expressed as $1 / 2[B-A]$, with gapdh expression being 1.0 , and $A=$ number of PCR cycles required to reach a certain intensity of fluorescence for the gapdh product, and $B=$ number of PCR cycles required to reach the same fluorescent intensity for the target gene product $(b c l-2)$ derived from the same sample. PCR products were confirmed to be successfully amplified by standard agarose gel electrophoresis and staining with ethidium bromide. Comparisons of the results for relative gene expression and proliferation assayed by real-time RT-PCR were analyzed using Fisher's parametric least significant difference (PLSD) test

after inhalation. Chrysotile is known to induce malignant transformation, but its carcinogenic capacity is lower than that of iron-containing asbestos, such as crocidolite and amosite [13-15].

We report here the immunological alterations of $\mathrm{MM}$ patients in an experimental background. These changes may have resulted from the immunological effects of asbestos on human immunocompetent cells and, as such, may provide valuable information that can be used in preventing the immunological changes seen in the occurrence and progression of asbestos-induced malignant diseases.

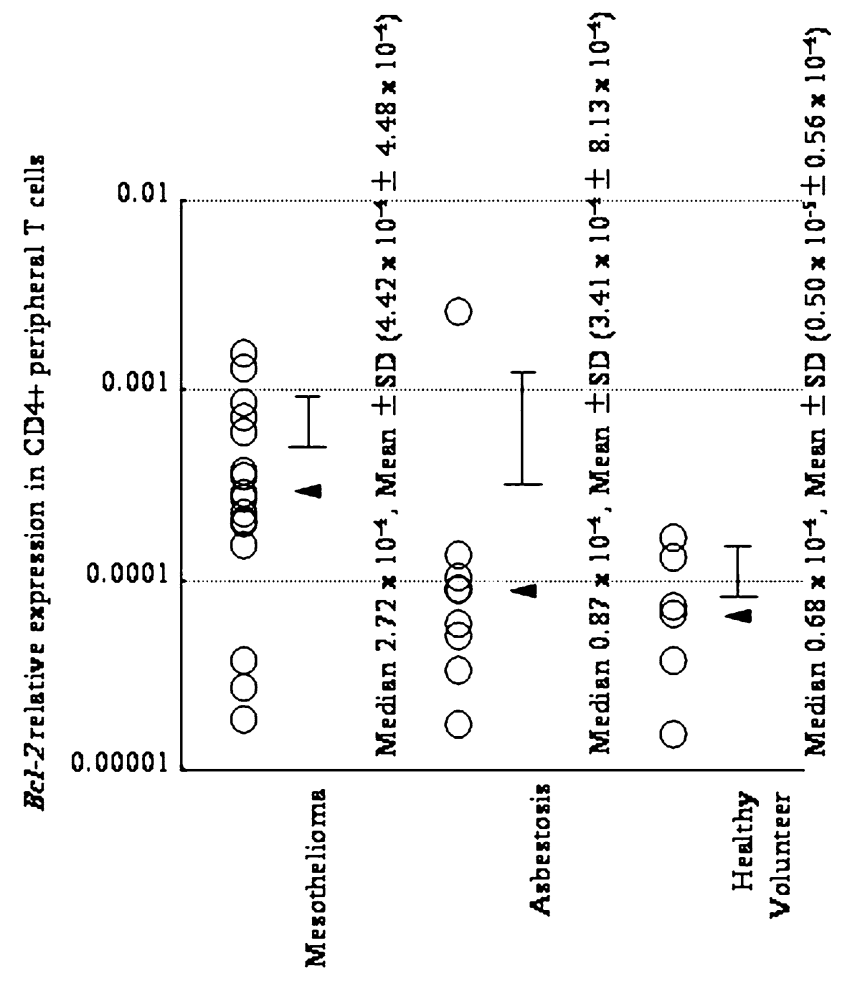

\section{bcl-2 expression of peripheral CD4+ T cells in MM patients}

Figure 1 shows that peripheral CD4+ T cells from MM patients express significantly more $b c l-2$ than healthy volunteers and asbestosis patients [16]. This may suggest that the overexpression of $b c l-2$ in peripheral CD4+ T cells is one of the markers of the occurrence of MM in asbestosexposed patients, although further study is necessary to determine whether many other cancer-bearing patients show the same change. The experimental background leading up to this finding is as follows.

We first exposed peripheral fresh $\mathrm{T}$ cells or $\mathrm{T}$ cellderived cell lines to high doses of chrysotile for a short time and found that a human T-cell leukemia virus type-1 (HTLV-1)-immortalized human polyclonal $\mathrm{T}$ cell line, MT-2, underwent apoptosis. This apoptosis progressed with reactive oxygen species (ROS) production via activation of the mitochondrial apoptotic pathway with the phosphorylation of $\mathrm{p} 38$ mitogen-activated protein kinase (MAPK) and c-Jun N-terminal kinase (JNK) signaling molecules. In addition, short-term, high-level exposure to chrysotile resulted in a shift of the Bax-dominant Bax/Bcl2 balance followed by the release of cytochrome-c from mitochondria into the cytosol and the activation of caspases 9 and 3 [17]. These observations led us to believe that an in vitro experimental model of chronic exposure was necessary both to analyze the immunobiological effects of 
silicates during long-term exposure and to be able to extrapolate these experimental findings to clinical analyses.

We therefore established a chrysotile-induced apoptosisresistant subline of MT-2 (MT-2Rst) and characterized the cell biological differences between the original MT-2 cell line (MT-2Org) and MT-2Rst. MT-2Rst cells were characterized by (1) an enhanced expression of $b c l-2$, restoring apoptosis sensitivity with the decrease in $b c l-2$ expression level by siRNA, (2) excessive IL-10 secretion and expression and (3) the activation of STAT3 inhibited by 4amino-5-(4-chlorophenyl)-7-(t-butyl) pyrazolol [3,4- $d]$ pyrimidine (PP2), a specific inhibitor of the Src family kinases. These findings suggest that contact between cells and asbestos may affect the human immune system and trigger a cascade of biological events, such as the activation of Src family kinases, enhancement of IL-10 expression, STAT3 activation and Bcl-2 overexpression, as previously reported [16].

Another interesting finding was obtained from analyses using bcl-2 expression in peripheral $\mathrm{CD} 4+\mathrm{T}$ cells. We performed factor analysis using various clinical parameters and individual $b c l-2$ relative expression ratios ( $b c l-2$ RER) obtained by real-time RT-PCR from MM patients. This analysis revealed that $b c l-2$ RER, a past history of asbestos exposure, peripheral platelet counts and serum CRP values formed one factor and that each parameter was related as higher, present, lower count, and lower value, respectively, as shown in Table 1. Platelet-derived growth factor (PDGF) is one of the most known mesothelioma-related

Table 1 Factor analysis in clinical parameters of mesothelioma patients with relative $b c l-2$ expression in peripheral CD4+ T cells

\begin{tabular}{lc}
\hline Parameter & $\begin{array}{l}\text { Value } \\
\text { (value more than } \pm 0.4 \text { is } \\
\text { considered to contribute to } \\
\text { form this factor) }\end{array}$ \\
\hline $\begin{array}{ll}b c l-2 \text { relative expression ratio } \\
\text { in peripheral CD4+ T cells }\end{array}$ & $\mathbf{0 . 5 9 0 0 9}$ \\
Histology (numbered) & -0.14234 \\
Epithelial type $=1$ & \\
Mixed type $=2$ & \\
Sarcomatous type $=3$ & $\mathbf{0 . 5 5 4 9 6}$ \\
Past asbestos exposure (numbered) & \\
Existence $=1$ & \\
Unknown $=2$ & \\
None $=3$ & \\
Count of WBC & \\
Count of platelets & \\
Concentration of serum creatinin & 0.22054 \\
Concentration of serum CRP & $\mathbf{- 0 . 7 6 0 6 4}$ \\
Contribution rate & $\mathbf{- 0 . 7 9 7 8 9}$ \\
\hline
\end{tabular}

growth factors, and it functions as the autocrine/paracrine proliferation-promoting factor for mesothelioma cancer cells [18-21]. Although higher serum levels of PDGF in MM patients are thought to be produced from mesothelioma cells and $b c l-2$ RER is a known marker of $\mathrm{T}$ cells chronically exposed to asbestos, there may be unknown biological mechanisms between immunocompetent cells with chronic exposure to asbestos and peripheral platelet counts via PDGF.

\section{$\mathrm{T}$ cell receptor $(\mathrm{TCR}) \mathrm{V} \beta$ expression}

We have previously reported that asbestos may act on peripheral $\mathrm{T}$ cells as a superantigen [22-24]. The effects of a superantigen, such as staphylococcal enterotoxin B (SEB), may modify $\mathrm{TCRV} \beta$ on peripheral $\mathrm{T}$ cells to enhance multiple, but not clonal, TCRV $\beta$ expression [25-28]. As shown in Fig. 2, various TCRV $\beta$ s were overexpressed in $\mathrm{MM}$ and asbestosis patients. There was a higher expression

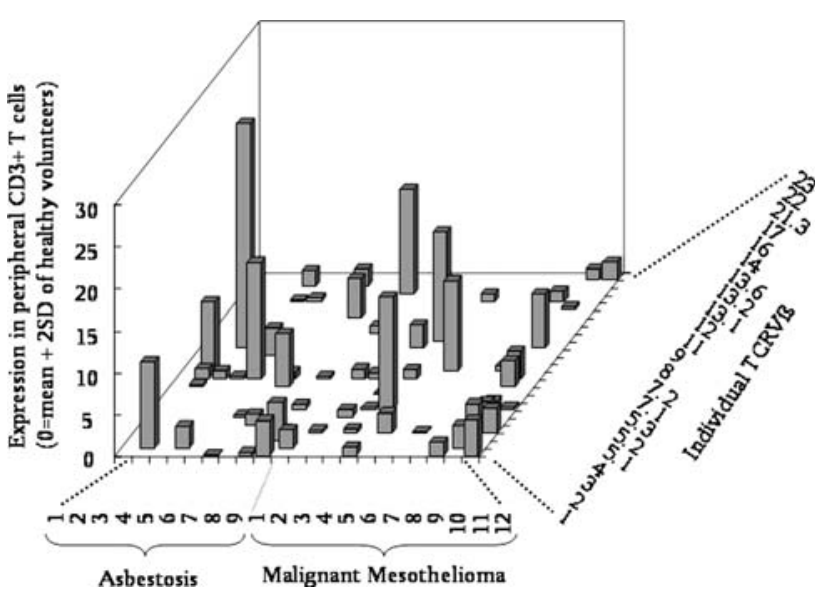

Fig. $2 \mathrm{~T}$ cell receptor (TCR) $\mathrm{V} \beta$ expression among patients with asbestosis and MM. Peripheral blood mononuclear cells were obtained from six healthy volunteers $[\mathrm{HV}$; mean age $\pm \mathrm{SD}$ : $38.0 \pm 6.4$ years; male $(\mathrm{M})$ :female $(\mathrm{F}): 1: 5]$, nine asbestosis patients without significant clinical signs of complications, such as lung cancer or malignant mesothelioma (ASB; $74.4 \pm 3.9$; all males) and 12 patients with $\mathrm{MM}(58.7 \pm 10.1 ; \mathrm{M}: \mathrm{F}: 9: 3)$. Specimens were taken only once informed consent had been obtained. The study was approved by the Ethics Committee of Kawasaki Medical School, Okayama Rosai Hospital, Hyogo College of Medicine and Kusaka Hospital. The expression of TCRV $\beta$ in CD3+ cells derived from HV, ASB and MM subjects was examined with an IOTest Beta Mark $\operatorname{TCRV} \beta$ repertoire analysis kit (Beckman Coulter, Fullerton, CA) using a FACSCalibur flowcytometer (Becton, Dickinson and Company, Franklin Lakes, NJ) according to the manufacturer's instructions. This kit can analyze TcRV $\beta 1,-2,-3,-4,-5.1,-5.2$, $-5.3,-7.1,-7.2,-8,-9,-11,-12,-13.1,-13.2,-13.6,-14,-16,-17,-18$, $-20,-21.3,-22$ and -23 from $1 \mathrm{ml}$ of peripheral blood. The $0 \%$ expression in this figure is the mean $+2 \mathrm{SD}$ of HV. Thus, each bar indicates how many overexpressions were observed in individual patients and individual TVRV $\beta$ s 
Fig. 3 Experimental findings on the immunological effects of chrysotile, a form of asbestos, induced by short-term and highdose exposure or long-term and low-dose exposure using MT-2, an HTLV-1 immortalized human polyclonal $\mathrm{T}$ cell line

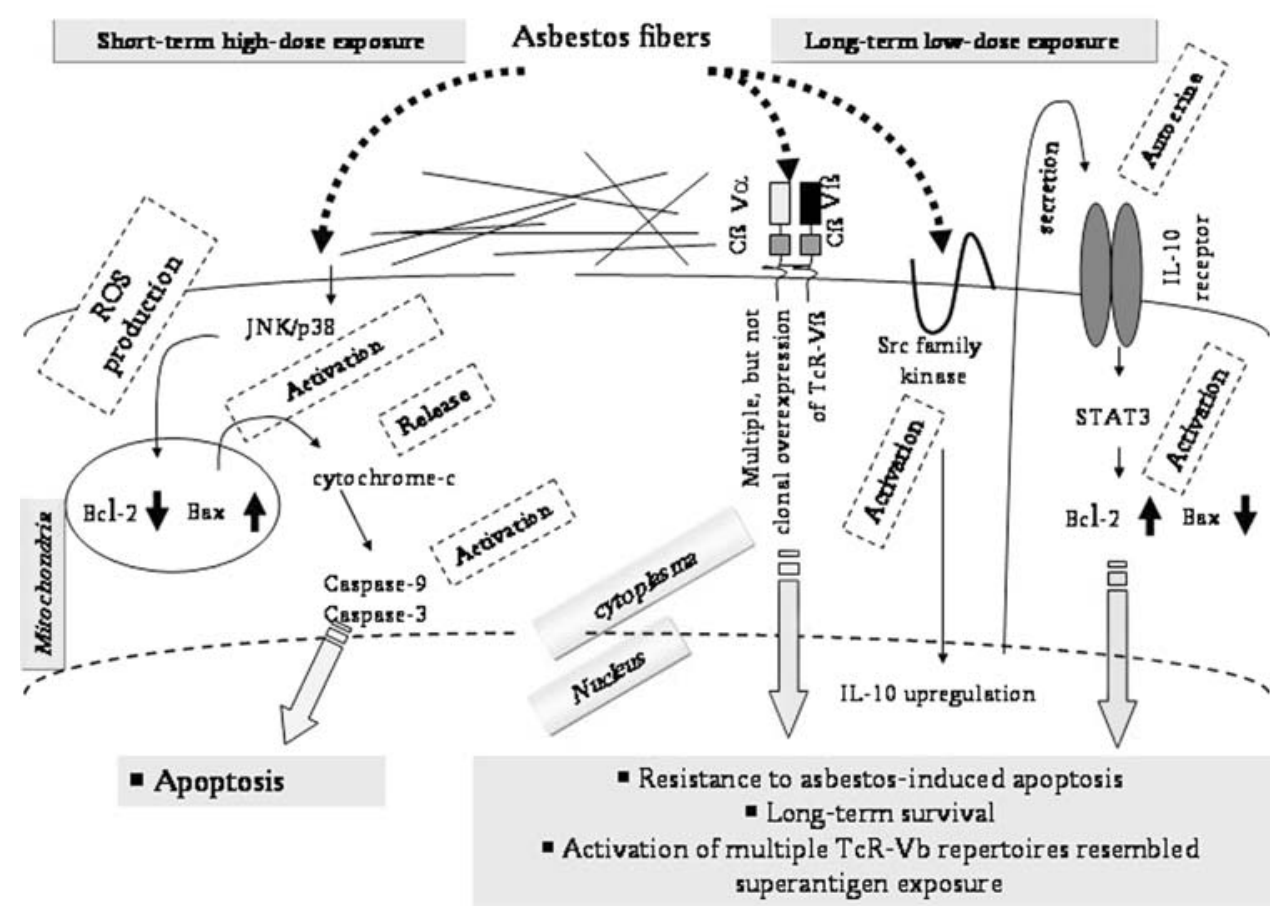

of TCRV $\beta$ s in patients, which exceeded the average plus 2 SD (standard deviation) limit randomly. In addition, several TVRV $\beta$ s, such as V $\beta 1,-4$ and -9 , among 24 kinds of TVRV $\beta$ were strongly overexpressed in many patients. This overexpression was also observed when TCRV $\beta$ expression in MT-2Org and MT-2Rst cell lines was compared, revealing that MT-2Rst cells overexpressed various TcRV $\beta$ s. Although TcRV $\beta$-overexpressing MT-2Org cells underwent apoptosis due to their first contact with chrysotile, MT-2Rst cells showed no significant changes when they again came in contact with chrysotile [29]. These findings may be interpreted as follows: the overexpression of various $\operatorname{TcRV} \beta$ s may be the result of contact between cells and chrysotile, an asbestos fiber, during the acquisition of resistance to chrysotile-induced apoptosis caused by long-term and low-dose exposure to chrysotile [29].

The multiple overexpression of TCRV $\beta \mathrm{s}$ in $\mathrm{CD} 3+$ peripheral $\mathrm{T}$ cells derived from asbestos-exposed patients may be one of the candidates for detecting prior asbestos exposure. Although these data were obtained from a limited number of patients, it is worth continuing these analyses using samples from many patients and also to explore the biological mechanisms involved in these findings.

\section{Conclusion}

The schematic presentation shown in Fig. 3 summarizes our experimental and clinical findings related to asbestos exposure of $\mathrm{T}$ cells. We have been investigating the effects of asbestos on the function of natural killer (NK) cells from cellular and molecular viewpoints. In addition, similar to the case of PDGF, TGF- $\beta 1$ is also known as a mesothelioma-producing growth factor [30-33]. Thus, the effects of TGF- $\beta 1$ on asbestos-exposed MT-2Rst cells are currently under investigation, including a comparison of these effects with those on MT-2Rst cells which are not exposed to TGF- $\beta 1$, or MT-2Org. cells. The results of these studies will be presented in the near future.

Recent advances in immunomolecular studies have led to detailed analyses of the immunological effects of asbestos. Asbestos affects immunocompetent cells, and these effects may be associated with the pathophysiological development of complications in asbestos-exposed patients, such as malignant tumors. In addition, immunological analyses may lead to the new discovery of clinical tools for the modification of pathophysiological aspects of diseases, such as the regulation of tumor immunity using cell-mediated therapies, various cytokines and moleculetargeting therapies. As the incidence of asbestos-related malignancies is increasing and such malignancies have been a medical and social problem since the summer of 2005 in Japan, efforts should be focused on developing a cure for these diseases to eliminate the nation wide anxiety about these malignancies.

Acknowledgments The authors wish to thank Ms. Tamayo Hatayama, Minako Kato, Naomi Miyahara, Misao Kuroki, Keiko Kimura, Tomoko Sueishi, Yoshiko Yamashita, Satomi Hatada, Yumika Isozaki and Haruko Sakaguchi for technical assistance. The data 
obtained in the Department of Hygiene, Kawasaki Medical School and published by the authors were supported by Special Coordination Funds for Promoting Science and Technology (H18-1-3-3-1), JSPS KAKENHI (17790375, 18390186, 19689153, 19790431 and 19790411), Kawasaki Medical School Project Grants (16-212, 16401N, 17-210S, 7-404M, 17-611O, 18-209T, 18-403 and 18-601), a Sumitomo Foundation Grant (053027), and a Yasuda Memorial Foundation Grant (H18)

\section{References}

1. Becklake MR, Bagatin E, Neder JA. Asbestos-related diseases of the lungs and pleura: uses, trends and management over the last century. Int J Tuberc Lung Dis. 2007;11:356-69.

2. O'Reilly KM, Mclaughlin AM, Beckett WS, Sime PJ. Asbestosrelated lung disease. Am Fam Physician. 2007;75:683-8.

3. Niklinski J, Niklinska W, Chyczewska E, Laudanski J, Naumnik W, Chyczewski L, Pluygers E. The epidemiology of asbestosrelated diseases. Lung Cancer. 2004;Suppl 1:S7-15.

4. Cooper GS, Parks CG. Occupational and environmental exposures as risk factors for systemic lupus erythematosus. Curr Rheumatol Rep. 2004;6:367-74.

5. Hess EV. Environmental chemicals and autoimmune disease: cause and effect. Toxicology. 2002;181-182:65-70.

6. Cooper GS, Miller FW, Germolec DR. Occupational exposures and autoimmune diseases. Int Immunopharmacol. 2002;2(23):303-13.

7. Caplan A. Certain unusual radiological appearances in the chest of coal-miners suffering from rheumatoid arthritis. Thorax. 1953;8(1):29-37.

8. Caplan A, Cowen ED, Gough J. Rheumatoid pneumoconiosis in a foundry worker. Thorax. 1958;13:181-4.

9. Caplan A. Rheumatoid disease and pneumoconiosis (Caplan's syndrome). Proc R Soc Med. 1959;52:1111-3.

10. Shons AR, Schubert W. Silicone breast implants and immune disease. Ann Plast Surg. 1992;28:491-9.

11. Hirmand H, Latrenta GS, Hoffman LA. Autoimmune disease and silicone breast implants. Oncology (Williston Park). 1993;7: $17-24$.

12. Brown SL, Langone JJ, Brinton LA. Silicone breast implants and autoimmune disease. J Am Med Womens Assoc. 1998;53: 21-24, 40.

13. Harington JS. The carcinogenicity of chrysotile asbestos. Ann N Y Acad Sci. 1991;643:465-72.

14. Fattman CL, Chu CT, Oury TD. Experimental models of asbestos-related diseases. In: Roggli VL, Oury TM, Sporn TA, editors. Asbestos-associated diseases. New York: Springer Science + Business Media; 2004. p. 256-308.

15. Lemen RA. Epidermiology of asbestos-related diseases and the knowledge that led to what is known today. In: Dodson RF, Hammar SP, editors. Asbestos: risk assessment, epidemiology, and health effects. Boca Raton, FL: CRC; 2006. p. 201-308.

16. Miura Y, Nishimura Y, Katsuyama H, Maeda M, Hayashi H, Dong $\mathrm{M}$, Hyodoh $\mathrm{F}$ et al. Involvement of IL-10 and Bcl-2 in resistance against an asbestos-induced apoptosis of $\mathrm{T}$ cells. Apoptosis. 2006;11:1825-35.

17. Hyodoh F, Takata-Tomokuni A, Miura Y, Sakaguchi H, Hatayama T, Hatada S, Katsuyama $\mathrm{H}$ et al. Inhibitory effects of antioxidants on apoptosis of a human polyclonal T-cell line, MT-2, induced by an asbestos, chrysotile-A. Scand J Immunol. 2005;61:442-8.
18. Gerwin BI, Lechner JF, Reddel RR, Roberts AB, Robbins KC, Gabrielson EW, Harris CC. Comparison of production of transforming growth factor-beta and platelet-derived growth factor by normal human mesothelial cells and mesothelioma cell lines. Cancer Res. 1987;47:6180-4.

19. Versnel MA, Bouts MJ, Langerak AW, van der Kwast TH, Hoogsteden $\mathrm{HC}$, Hagemeijer A, Heldin CH. Hydrocortisoneinduced increase of PDGF beta-receptor expression in a human malignant mesothelioma cell line. Exp Cell Res. 1992;200:83-8.

20. Klominek J, Baskin B, Hauzenberger D. Platelet-derived growth factor (PDGF) BB acts as a chemoattractant for human malignant mesothelioma cells via PDGF receptor beta-integrin alpha3beta1 interaction. Clin Exp Metastasis. 1998;16:529-39.

21. Langerak AW, De Laat PA, Van Der Linden-Van Beurden CA, Delahaye M, Van Der Kwast TH, Hoogsteden HC, Benner R et al. Expression of platelet-derived growth factor (PDGF) and PDGF receptors in human malignant mesothelioma in vitro and in vivo. J Pathol. 1996;178:151-60.

22. Aikoh T, Tomokuni A, Matsukii T, Hyodoh F, Ueki H, Otsuki T, Ueki A. Activation-induced cell death in human peripheral blood lymphocytes after stimulation with silicate in vitro. Int $\mathrm{J}$ Oncol. 1998;12:1355-9.

23. Ueki A. Biological effects of asbestos fibers on human cells in vitro-especially on lymphovytes and neutrophils. Indust Health. 2001;39:84-93.

24. Ueki A, Nakashima M, Kishimoto T, Nakamura J, Kinugawa K, Sakaguchi H. Analysis of the expression of TcR V $\beta$ peretoires in patients with silicosis. J Occup Health. 1996;38:67-70.

25. Schubert MS. A superantigen hypothesis for the pathogenesis of chronic hypertrophic rhinosinusitis, allergic fungal sinusitis, and related disorders. Ann Allergy Asthma Immunol. 2001;87:181-8.

26. Li H, Llera A, Malchiodi EL, Mariuzza RA. The structural basis of $\mathrm{T}$ cell activation by superantigens. Annu Rev Immunol. 1999; 17:435-66.

27. Torres BA, Johnson HM. Modulation of disease by superantigens. Curr Opin Immunol. 1998;10:465-70.

28. Sumida T, Matsumoto I, Maeda T, Nishioka K. T-cell receptor in Sjogren's syndrome. Br J Rheumatol. 1997;36:622-9. Review.

29. Nishimura Y, Miura Y, Maeda M, Hayashi H, Dong M, Katsuyama $\mathrm{H}$, Tomita $\mathrm{M}$ et al. Expression of the $\mathrm{T}$ cell receptor Vbeta repertoire in a human $\mathrm{T}$ cell resistant to asbestos-induced apoptosis and peripheral blood $\mathrm{T}$ cells from patients with silica and asbestos-related diseases. Int J Immunopathol Pharmacol. 2006; 19:795-805.

30. Suzuki E, Kapoor V, Cheung HK, Ling LE, DeLong PA, Kaiser LR, Albelda SM. Soluble type II transforming growth factor-beta receptor inhibits established murine malignant mesothelioma tumor growth by augmenting host antitumor immunity. Clin Cancer Res. 2004;10:5907-18.

31. Kuwahara M, Takeda M, Takeuchi Y, Kuwahara M, Harada T, Maita K. Transforming growth factor beta production by spontaneous malignant mesothelioma cell lines derived from Fisher 344 rats. Virchows Arch. 2001;438:492-7.

32. Maeda J, Ueki N, Ohkawa T, Iwahashi N, Nakano T, Hada T, Higashino K. Transforming growth factor-beta 1 (TGF-beta 1)and beta 2-like activities in malignant pleural effusions caused by malignant mesothelioma or primary lung cancer. Clin Exp Immunol. 1994;98:319-22.

33. Fitzpatrick DR, Bielefeldt-Ohmann H, Himbeck RP, Jarnicki AG, Marzo AL, Robinson BW. Transforming growth factor-beta: antisense RNA-mediated inhibition affects anchorage-independent growth, tumorigenicity and tumor-infiltrating T-cells in malignant mesothelioma. Growth Factors. 1994;11:29-44. 